IRA-International Journal of Education \&

Multidisciplinary Studies

QUARTERLY

ISSN 2455-2526; Vol.16, Issue 03 (July-Sep, 2020)

Pg. no. 194-198.

Institute of Research Advances

https://research-advances.org/index.php/IJEMS

\title{
Analyzing the Students' Behavior Characteristics of Learning College English Vocabulary
}

Fang Xu

School of Foreign Studies, Yangtze University, Jingzhou, Hubei, China.

Type of Work: Peer-Reviewed

DOl: http://dx.doi.org/10.21013/jems.v16.n3.pg

\section{How to cite this paper:}

Fang Xu (2020). Analyzing the Students' Behavior Characteristics of Learning College English Vocabulary. IRA International Journal of Education and Multidisciplinary Studies (ISSN 2455-2526), 16(3), 194-198. DOI: http://dx.doi.org/10.21013/jems.v16.n3.p9

(c) Institute of Research Advances.

This work is licensed under a Creative Commons Attribution-NonCommercial 4.0 International License subject to a proper citation to the publication source of the work.

Disclaimer: The scholarly papers as reviewed and published by the Institute of Research Advances (IRA) are the views and opinions of their respective authors and are not the views or opinions of the IRA. The IRA disclaims of any harm or loss caused due to the published content to any party.

Institute of Research Advances is an institutional publisher member of Publishers International Linking Association Inc. (PILA-CrossRef), USA. The institute is an institutional signatory to the Budapest Open Access Initiative, Hungary advocating the open-access of scientific and scholarly knowledge. The Institute is a registered content provider under Open Access Initiative Protocol for Metadata Harvesting (OAI-PMH).

The journal is indexed \& included in WorldCat Discovery Service (USA), CrossRef Metadata Search (USA), WorldCat (USA), OCLC (USA), Open J-Gate (India), EZB (Germany) Scilit (Switzerland), Airiti (China), Bielefeld Academic Search Engine (BASE) of Bielefeld University, Germany, PKP Index of Simon Fraser University, Canada. 


\begin{abstract}
The paper is aimed for three tasks: to review why learning vocabulary matters, what's in a word and what knowing a word means, to demonstrate the students' behavior characteristics of learning vocabulary through the result analysis of a questionnaire survey and interviews and to provide enlightenment about the future teaching and learning of college English.
\end{abstract}

Keywords: College English vocabulary; students' learning behavior characteristics; implication

\title{
1. Introduction
}

All languages have words. Some linguists have similar opinions on the significance of vocabulary learning. David Wilkins(1972) said: "Without grammar very little can be conveyed, without vocabulary nothing can be conveyed." His view was echoed by Michael McCarthy(1990): No matter how well the student studies grammar, no matter how successfully the roots of L2 are mastered, Without words to express a wider range of meanings, communication in an L2 just can't happen in any meaningful way. From their point of view, vocabulary is the primary and indispensable vehicle for communication when compared with the two other elements of the language system: sound and grammar.

\section{Vocabulary and the Essence of Vocabulary Acquisition}

Vocabulary is commonly defined as "all the words that a person knows and uses". Knowing a word, however, is not as simple as merely being able to recognize its sound, form and a single meaning. Some linguists agree that a specific system of vocabulary knowledge includes frequency and stylistic appropriateness of words, collocations with other words and association between words as well as its conceptual meaning, oral form (pronunciation), written form (writing), grammatical form (syntactic structures). Scott Thornbury(2008) explained in his book How to Teach Vocabulary: Unlike the learning of grammar, which is essentially rule-based system, vocabulary knowledge is largely a question of accumulating individual items. There are few short cuts in the form of generative rules: It is essentially a question of memory. Learning is remembering. Students are undoubtedly the main body of the memory task, and no one can replace them. Scott further pointed out: Not all the vocabulary knowledge that the learners need can be "taught", and learners will need plenty of exposure to vocabulary exercises as well as training for self-directed learning.

The significance of vocabulary learning tells learners why to learn, the vocabulary knowledge tells learners what to learn and the essence of vocabulary acquisition tells learners how to learn. However, "learning" is not "telling". What is learning? Learning is actually the act, process, or experience of gaining knowledge or skill, which leads to a potential change in synthesizing information, depth of the knowledge, attitude or behavior relative to the existing situation. Only when students, the subjects of the act, are aware of the importance of vocabulary learning, recognize their own level of vocabulary knowledge and language ability, find out the problems and are motivated to solve them in vocabulary learning, the act of vocabulary learning really happen, thus making personal development possible.

\section{Features of Vocabulary Learning Behavior}

Through a questionnaire survey and interviews conducted recently among my first-year students majoring in International Trade and Biological Engineering, the behavioral features of their vocabulary learning were detected: 
- Students have a better understanding of the importance of vocabulary learning and the dominant position of individuals in vocabulary learning.

- Students clearly show the difficulty that they have in vocabulary learning, for example: They can't memorize the words, they forget the words in a short time, they can't use them on appropriate occasions, they are tired of word learning and they are impatient to remember words.

- Students make attempts to use the Word Learning apps, such as baicizan, maimemo, shanbay and VocabGo to improve the current situation, making the most of the deepening integration of information technology and the learning of college English vocabulary.

- Students attach much more importance to and have more desire for peer competition and teachers' supervision than ever when they learn words independently out of class.

As can be seen, how students behave in the act of learning vocabulary displays not only individual characteristics, like learning preference, learning style and learning motivation, but group characteristics, say, their mutual needs for learning guidance and learning companions.

Can you recall the understanding of learning mentioned previously? What's your understanding of learning behavior? According to some psychologists, learning behavior can be viewed as a series of things that students do exactly in the process of learning. Learning behavior, especially in a specific learning environment, is regarded as the concrete behavioral forms and methods adopted by learners, which demonstrate learners' thoughts, emotions, motives, abilities and operating procedures. The ultimate goal of analyzing the characteristics of learning behavior is to predict the tendency of learners' learning behavior so as to better guide the future behavior in the practice of learning words.

\section{Implications for Vocabulary Instruction}

\subsection{Introducing learning theories to students}

The introduction of learning theories has been ignored by teachers of English as a foreign language. Teachers are surer of the roles they play in vocabulary teaching from Constructive Learning Theory and gain insights into more dimensions to teach words from Deeper Learning Theory. But will learning theories benefit students?

Constructive Learning Theory stresses that learning is an active process in which teachers will not instill what's new into learners' minds, but learners are supposed to give full play to their initiative and construct new ideas and concepts based on their past or current knowledge. Students assimilate, integrate and internalize new information, understanding and skills, thus developing a new cognitive system from an old one. Although subconsciously, students identify themselves as the decisive factor of learning results, they almost don't know the principles supporting an effective learning, thus making their behavior casually and temporarily. Constructive learning theory supplies students with a solid theoretical basis and enables them to know the rules and procedures leading to successful learning. Only when students realize it is they themselves (not teachers) who should be responsible for their own learning and it is a long and complex process that every student should experience (no one can get away), will they pull their energy and passion into learning for a long time.

Deep learning theory is another theory that is related to constructive learning theory, guiding students' vocabulary learning. 
Compared with passive and mechanical learning, deep learning is an active and critical way to achieve effective learning. It advocates that knowledge should be actively accepted as interrelated facts by paying attention to deep processing, deep understanding and long-term maintenance of knowledge, and making real knowledge construction, transfer and application and problem solving. Deep learning theory informs students of the complexity of learning and the relevance between things. The simplest words are typically those having a single meaning, a single part of speech, and used on few occasions. But, most of the things in the world are more complicated and interrelated with other things, so are the vast majority of the words. Polysemes, synonyms, antonyms and collocations, all reflect the correlation between words, and also remind students of what is involved in knowing a word really.

The introduction of the learning theories will benefit students in some ways.

\subsection{Avoiding making decisions for students}

The remarkable vocabulary learning behavior of students through this semester is the use of VocabGo. The difference between VocabGo and other mobile apps selected by students lies in one prominent point: There is a "port for students" to do vocabulary practice independently and a "port for teachers" to assign tasks online. The forms of vocabulary practice are diverse, the mode is optional, and the difficulty level is increasingly rising, all of which urge students to think carefully, deepen their understanding and strengthen their application in different contexts. Teachers assign class tasks, observe the engagement and performance of students, fulfilling the functions of teachers' supervision and support in the course of students' autonomous learning. Students are the main body of vocabulary learning, but the group characteristics of learning behavior show that they are eager for experience exchange and healthy competition among classmates and scientific organization and efficient management of teachers.

What does the utilization of VocabGo reflect? One, students have an acute judgement, choosing the proper learning apps in response to the deeper integration of information technology and vocabulary learning. Two, they have the ability to distinguish the one(s) from the rest, satisfying their own requirements for word learning. Avoid making decisions for students and offer guidance where necessary.

\subsection{Utilizing the strategies}

The learning strategies here include the strategies used both by students to memorize vocabulary and by teachers to organize vocabulary teaching. The results of this survey show that the students are faced with much difficulty in vocabulary learning. Forgetting is Top One on the list. Applying the learning strategies to help remember words is strongly suggested, like making the articulatory loop go round and round, using a word's rhymes, connecting the sound of a new word and an image or picture of the word, making sentences with new words, physically acting out new words, remembering a word's location on the page, on the board, or on the street sign ... All these serve as the remedies for forgetting in terms of students. When teaching students a new set of words, for example, it is best to present the first two or three times, then go back and test them, then present some more, then backtrack again, and so on. As for teachers, thinking about the way how teachers present words, the number of words presented at a time and the length of intervals between testing and making arrangement in a scientific way is a good try. Both teachers and students should face up to the law of forgetting and increase the awareness of what strategies can be used to teach and learn words in order to improve the vocabulary learning effectively. 


\section{Conclusion}

Holec(1981) thinks that autonomy is a potential for learners to take charge of their own learning. This kind of ability is not innate, but can only be acquired through natural means or systematic learning. The design of the items in this questionnaire aims to, on one hand, investigate the current situation of college English vocabulary learning and find out the learning behavior characteristics, which can be used to guide the future teaching practice of vocabulary; On the other hand, guided by questions, students are drawn to experience the essence of autonomous learning in the process of vocabulary learning, that is, according to personal needs and existing knowledge, a series of activities - determining individualized learning goals, making learning plans, adopting learning strategies, selecting learning materials, and evaluating learning effects - are carried out. Judging from the self-evaluation of the level of vocabulary knowledge and language ability, difficulties in learning, selection and use of learning resources and learning strategies, students basically have the will and ability to be responsible for their own learning, which will be strengthened in the future practice.

Vocabulary is often compared to bricks of a building and it is the basic unit of language. It will be meaningful to build learners' autonomous awareness and ability through the process of learning vocabulary, and transfer the self-learning planning ability, self-control ability, self-motivation ability, information processing ability and the ability to communicate and cooperate gradually acquired in vocabulary learning to the process of improving the comprehensive application ability of college English in more complex contents.

This paper is a staged achievement of the research project "Cultivation of Autonomous Learning Ability Based on College English Learning Platform” (Project No. JY2018022. Yangtze University)

\section{References:}

[1]. Chai Yangli, The Survey Research on the Current Situation and the WeChat Requirements of the English Audio-visual Teaching[J], Technology Enhanced Foreign Language Education, 2014(9): 66-72

[2]. Scott Thornbury, How to teach vocabulary[M]. Addison Wesley Longman, 2008

[3]. Shu Dingfang, On a New Model for Classroom Instruction in FLT[J], Foreign Language World, 2006(4): 21-29

[4]. Zhang Xueshun, Cui Guangjin, Teaching Strategy for Deep Learning of English Vocabulary[J], Journal of Teaching and Management.2020(4): 56-59

[5]. Liu Hui, Kang Wenyan, A Knowledge Graph of Deep Learning Research in China - Based on the Visual Analysis of 381 Chinese Core Journal Papers[J], Theory and Practice of Education, 2020(1): 50-55

[6]. Shen Yafen, On Deep Teaching of Junior English Vocabulary based on Deep Learning Theory[J], English Teachers, 2018(20): 113-117

[7]. Zhang Hao, Wu Xiujuan. On the Connotation and Cognitive Theoretical Basis of Deep Learning[J]. China Educational Technology. 2012(10): 7-11+21

[8]. Yu Qian. Analysis of Group Characteristics of Learners' Learning Behavior Based on Campus-network Independent Learning[D]. Shaanxi Normal University. 2007

[9]. Yan Song. The Teaching Status of "University English" and the Application Research of WeChat Platform in the Teaching of "University English" - Taking a University in Southwest China as an Example[D]. Southwest University of Science and Technology.2020

[10]. Hua Weifen. On Learner Autonomy[J]. Journal of Shenzhen University (Humanities \& Social Sciences). 2002(3): $107-112$. 